\section{Computed Tomography Angiogram in Diagnosis of Churg-Strauss Vasculitis}

\section{To the Editor:}

A novel diagnostic approach may be a helpful adjunct to clinical judgment in evaluating Churg-Strauss syndrome.

A 51-year-old African American man with a 1-year history of asthma treated with inhalers, mometasone, and monteleukast presented to his primary care provider with 6 weeks of numbness and tingling of the hands and feet followed by dusky discoloration and pain in the fourth and fifth digits of the right hand. Similar changes occurred in the left hand 1 week later. $\mathrm{He}$ had a nonpruritic rash with associated ulcerations of the pretibial region bilaterally. A computed tomography angiogram (CTA) of the legs demonstrated multiple focal areas of dilatation and stenosis. A beaded appearance was evident throughout the posterior tibial arteries bilaterally that extended into the common plantar and lateral plantar arteries (Figure 1).

Retinal examination revealed bilateral ischemic changes suggestive of embolic or vasculitic phenomenon. There was infarction of the distal portions of the fourth and fifth digits of the right hand, and splinter hemorrhages of the nails were noted bilaterally (Figure 2). Non-excoriated ulcerations $1-2 \mathrm{~mm}$ in diameter were noted in the pretibial area (Figure 2). Neurologic examination demonstrated decreased sensation to light touch in both feet and in both hands along an ulnar distribution. Complete blood cell count showed significant eosinophilia of $2722 / \mathrm{mm}^{3}$ without leukocytosis; chemistry results showed no evidence of renal insufficiency. Chest radiography, urinalysis, erythrocyte sedimentation rate, C-reactive protein, complement 3 and 4 levels, hepatitis $B$ and $\mathrm{C}$, antineutrophil cytoplasmic antibody (ANCA), and rheumatoid factor were unremarkable. A transesophageal echocardiogram revealed no embolic source. An electromyogram with nerve conduction testing showed bilateral peroneal nerve neuropathy consistent with an early vasculitis. A skin biopsy of the pretibial ulcerations showed an eosinophilic infiltrate in the arteries and venules consistent with either Churg-Strauss syndrome or polyarteritis nodosa. The patient met 4 of the American College of Rheumatology (ACR) diagnostic criteria for Churg-Strauss syndrome ${ }^{1}$. He was prescribed $1 \mathrm{mg} / \mathrm{kg}$ prednisone and discharged home. On followup, his vascular symptoms continued to improve, although the prolonged ischemic digital changes required extensive debridement.

Churg-Strauss syndrome was originally described in a study of polyarteritis nodosa, and is characterized by the triad of asthma, eosinophilia, and vasculitis ${ }^{2}$. The incidence of Churg-Strauss is 2.4 to 4.0 per 1,000,000. The mean age at onset is 50 years (range 14-75 yrs). The etiology of the disease is unclear, but is likely autoimmune ${ }^{3}$.

The diagnosis of Churg-Strauss is based on a biopsy of affected tissues, traditionally an open-lung biopsy. ANCA are positive in $38 \%$ and perinuclear in $90 \%$, and are strongly associated with renal involvement ${ }^{4}$. Following the ACR diagnostic criteria ${ }^{1}$, presence of 4 of the following 6 criteria makes the diagnosis with $99.7 \%$ specificity: (1) asthma; (2) eosinophilia $>10 \%$; (3) mononeuropathy or polyneuropathy; (4) migratory or transient pulmonary opacities; (5) paranasal sinus abnormality; (6) biopsy showing accumulation of eosinophils in extravascular areas.

While highly specific, these diagnostic criteria suffer from poor sensitivity since many of the symptoms are fleeting. Another diagnostic modality that has been used extensively in other types of vasculitis is digital subtraction angiography. However, there is a $2 \%-3 \%$ complication rate, including contrast nephropathy, peripheral or central venous infection, embolic events, arterial wall dissection, and pseudoaneurysm formation and rupture ${ }^{5}$. CTA was initially studied in Takayasu's arteritis, and more recently polyarteritis nodosa, and was found to aid in the diagnosis with minimal risk of complications ${ }^{6-11}$. Since there is significant overlap between Churg-Strauss syndrome and polyarteritis nodosa, it stands to reason that CTA can be of use. An evaluation of the literature reveals a paucity of data regarding the use of CTA in the Churg-Strauss syndrome.

In addition to the prototypical presentation of a rare vasculitis, our case demonstrates a novel diagnostic approach that may be a helpful adjunct to

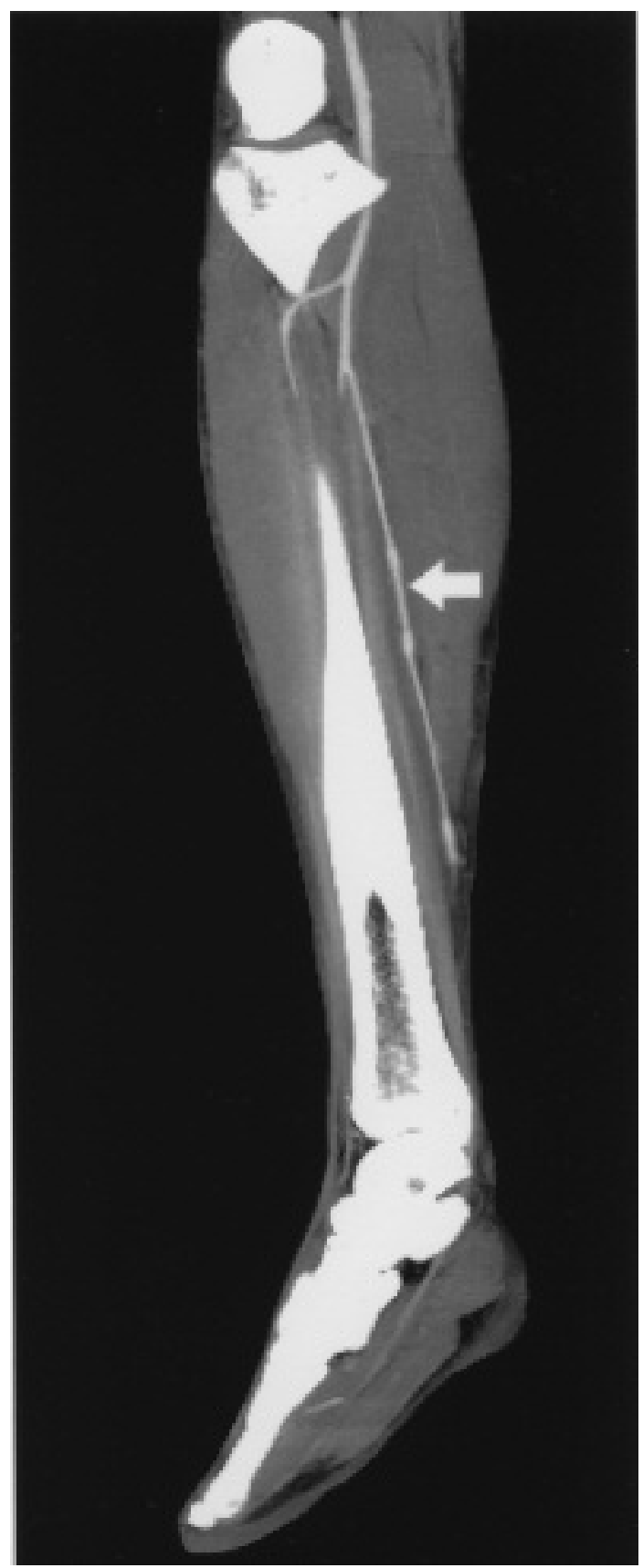

Figure 1. CT angiography of the right lower extremity showing multiple focal areas of dilatation with a beaded appearance of the posterior tibial artery (arrow), extending into the common plantar and lateral plantar arteries.

clinical judgment in evaluating Churg-Strauss syndrome. Since the CTA procedure subjects patients to little of the discomfort or risk of invasive angiography, further studies are warranted.

PAYAL C. DESAI, MD; EMILY S. KENNER, MD; BRYAN K. MOFFETT, MD, Associate Professor of Medicine, Internal Medicine, Department of Veterans Affairs, and Department of Internal Medicine, University of Louisville, 530 South Jackson Street, ACB, 3rd floor, Louisville, Kentucky 40202, USA. Address correspondence to Dr. Moffett; E-mail: bkmoffett@insightbb.com 


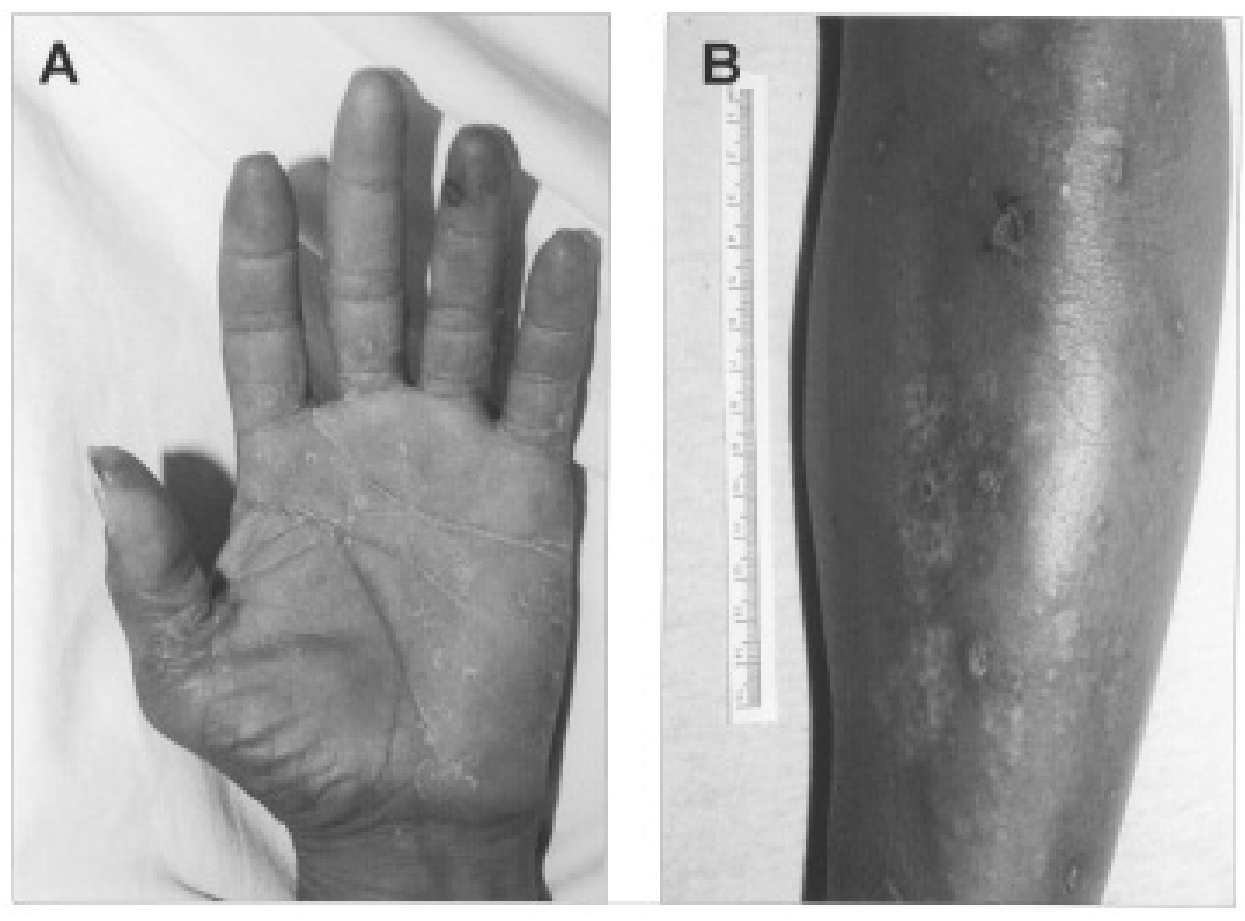

Figure 2. Cutaneous manifestations of Churg-Strauss vasculitis. A. Left hand shows distal digital artery infarction. B. Pretibial nodules and ulcerations.

The authors thank Dr. Darren L. Cain, Department of Radiology, University of Louisville.

\section{REFERENCES}

1. Masi AT, Hunder GG, Lie JT, Michel BA, Bloch DA, Arend WP, et al. The American College of Rheumatology 1990 criteria for the classification of Churg-Strauss syndrome (allergic granulomatosis and angiitis). Arthritis Rheum 1990;33:1094-100.

2. Churg J, Strauss L. Allergic granulomatosis, allergic angiitis, and periarteritis nodosa. Am J Pathol 1951;27:277-301.

3. Lhote F, Guillevin L. Polyarteritis nodosa, microscopic polyangiitis, and Churg-Strauss syndrome. Clinical aspects and treatment. Rheum Dis Clin North Am 1995;21:911-47.

4. Sable-Fourtasson R, Cohen P, Mahr A, Pagnoux C, Mouthon L, Jayne D, et al. Antineutrophil cytoplasmic antibodies and the Churg-Strauss syndrome. Ann Intern Med 2005;143:632-8.

5. Hessel SJ, Adams DF, Abrams HL. Complications of angiography. Radiology 1981;138:273-81.

6. Pinheiro LW, LeBlang SD, Romano J, Forteza A. The acute diagnosis of Takayasu's arteritis based on helical CT angiography of the chest and neck in the emergency room. AJNR Am J
Neuroradiol 1999;20:1983-5

7. Scatarige JC, Urban BA, Hellmann DB, Fishman EK. Three-dimensional volume-rendering $\mathrm{CT}$ angiography in vasculitis: spectrum of disease and clinical utility. J Comput Assist Tomogr 2001;25:598-603

8. Yoshida S, Akiba H, Tamakawa M, Yama N, Takeda M, Hareyama $\mathrm{M}$, et al. The spectrum of findings in supra-aortic Takayasu's arteritis as seen on spiral CT angiography and digital subtraction angiography. Cardiovasc Intervent Radiol 2001;24:117-21.

9. Schmidt WA. Use of imaging studies in the diagnosis of vasculitis. Curr Rheumatol Rep 2004;6:203-11.

10. Ozcakar ZB, Yalcinkaya F, Fitoz S, Yuksel S, Acar B, Caltik A, et al. Polyarteritis nodosa: successful diagnostic imaging utilizing pulsed and color Doppler ultrasonography and computed tomography angiography. Eur J Pediatr 2006;165:120-3.

11. Lin J, Chen B, Wang JH. Diagnosis of systemic arterial diseases with whole-body $3 \mathrm{D}$ contrast-enhanced magnetic resonance angiography. Chin Med J (Engl) 2006;119:1772-8.

J Rheumatol 2009;36:12; doi:10.3899/jrheum.090695 